\begin{tabular}{|c|c|c|}
\hline $\begin{array}{l}\text { EXCELLENT } \\
\text { PUBLISHERS } \\
\end{array}$ & 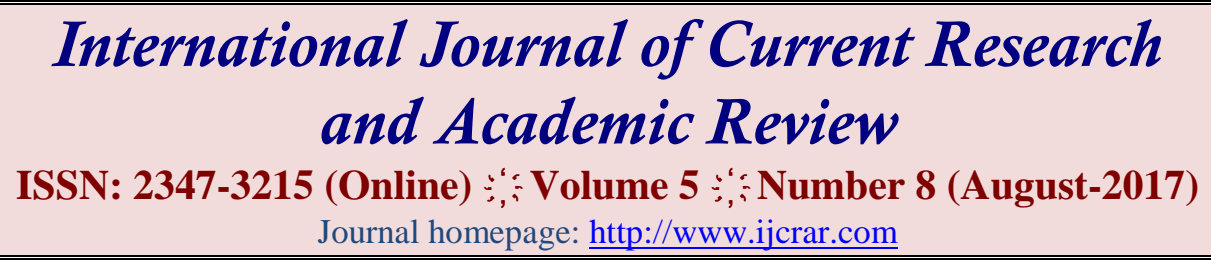 & 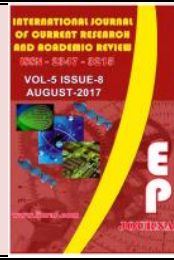 \\
\hline
\end{tabular}

doi: https://doi.org/10.20546/ijcrar.2017.508.002

\title{
In Vitro Propagation of Bambusa vulgaris through Branch Node
}

\author{
Hardik Gajjar ${ }^{1}$, Akhil Raval ${ }^{1}$, Hemangini Raval ${ }^{2}$, Harikrushna Patel $^{2}$ and Suthar Ramchandra ${ }^{2 *}$ \\ ${ }^{I}$ Department of Microbiology, Shree M.M. Patel Institute of Science \& Research, Kadi. KSV University, \\ Gandhinagar. Gujarat, India \\ ${ }^{2}$ Department of Biotechnology, P. S. Science \& H. D. Patel Arts College, Kadi-382517, HNGU University, Patan, \\ Gujarat, India
}

*Corresponding author

\section{Abstract}

Low cost, efficient and reproducible protocol has been established through the technique of Plant tissue culture forced branch node for the propagation of an important bamboo species namely Bambusa vulgaris. The propagation of B. vulgaris through branch node culture was studied. Single node segments were tested for budbreak and shoot growth on basic Murashige and Skoog (1962) medium (MS) supplemented with different combinations and concentrations of growth regulators. Results suggest that cytokinin is important for bud-break. The position of the node on the Culm appears to affect bud-break and multiplication, middle nodes are the most suitable. Also, removal of prophylls enhances bud-break. High frequency multiple shoot induction was achieved from branch nodal segments collected from elite genotype on Murashige and Skoog's (MS) medium supplemented with $1.5 \mathrm{mg} / 1$ 6Benzylaminopurine (BAP) and $2.0 \mathrm{mg} / \mathrm{l}$ Kinetin $(\mathrm{Kn})$. The size of explants and season greatly influenced the frequency of bud break. Best rooting response was observed on of Indole- 3 Butyric acid (IBA) $2 \mathrm{mg} / \mathrm{l}$ with $60 \%$ rooting. In vitro raised plants were successfully acclimatized and established in the field conditions where they exhibited normal growth.
\end{abstract}

\section{Article Info}

Accepted: 30 July 2017

Available Online: 20 August 2017

\begin{tabular}{l} 
Keywords \\
\hline MS media, \\
Bambusa, \\
Tissue culture and \\
Multiple shoot.
\end{tabular}

\section{Introduction}

Bamboo is a member of grass family (Poaceae: Bambusoideae) with the characteristics of short rotation, marketability of culms every year and immediate returns, bamboos are the fast growing multipurpose plants of high economic and environmental value that converts solar radiation into useful goods and services better than most tree species (Franklin, 2006; Kassahun, 2000).

Besides producing fresh edible shoots and culms for timber, furniture and handicraft or as a raw material for pulping, bamboo serves as an efficient agent for conservation of water and soil (Christanty et al., 1996, 1997; Kassahun, 2003; Kleinhenz \& Midmore, 2001; Mailly et al., 1997).There are about 88 genera and 1400 recorded species of bamboo in the world, 34 genera and 534 species of which are in China (Wu \& Raven, 2006).

Bamboo is found in an area of more than 14 million ha throughout the tropics, subtropics and temperate zones of the world. Eighty percent of the species and area are confined to South and Southeast Asia, and largely in China, India, and Myanmar. 
Currently, International Union for Conservation of Nature (IUCN) Red list of endangered bamboo species has included Bambusa bambos as a priority species and hence needs conservation (Bystriakova, et al., 2003). Limitations in traditional propagation methods such as the use of offsets, branch cuttings together with unpredictable and long flowering cycle (40-60 years) warrants an urgent need for an alternative approach for developing efficient and reproducible protocol for its mass propagation.

In vitro propagation or tissue culture technique holds tremendous potential for the production of high-quality planting material (Brar, et al., 2013).

\section{Materials and Methods}

\section{Collection and Selection of branch node}

Branch nodes were collected from 5 years old bamboo plants from Centre Agricultural college garden, Kadi, India.

\section{Surface sterilization of Node}

Branch Nodes were first pretreated with $1 \%$ aqueous bavistin solution (Fungicide) for $20 \mathrm{~min}$. Then they were soaked for $5 \mathrm{~min}$ in $20 \%$ solution of commercial bleach. Sterilization was done using $0.1 \% \mathrm{HgCl}_{2}$ solution for 3 min. and finally washed 4-6 times with autoclaved distilled water.

\section{Media}

Branch Nodes were cultured on MS medium augmented with different growth regulators, 3\% sucrose and $0.8 \%$ agar with $\mathrm{pH}$ adjusted to 5.8 before the addition solidifying agent. Various factors like initial response of explant, contamination rate, bud break and survival percentage were considered for initiation of cultures. Basal MS medium supplemented with a combination of two cytokinins viz BAP $(1.0,1.5 \& 2.0 \mathrm{mg} / \mathrm{l})$ and $\mathrm{Kn}$ $(1.5 \& 2.0 \mathrm{mg} / \mathrm{l})$ with sucrose $(3 \%)$ was tested for standardization of axillary proliferation. For root induction, shoots were excised in clumps of 3-4 from multiple shoot bunches and transferred onto MS media in half strengths supplemented with IBA $(1.0,2.0 \& 3.0$ $\mathrm{mg} / \mathrm{l})$ with $0.8 \%$ agar. The rooted plantlets were hardened on sand, soil and farmyard manure (1:1:1) under greenhouse conditions and finally transferred to full sunlight.

\section{Branch Node Culture}

Sterilized branch node were cut $2-3 \mathrm{~cm}$ and inoculated in glass bottles (fig.-1). Each bottles contained 4-5 nodes. Individual bottles were wrapped with parafilm to maintain it free from contamination and incubated under light at $26^{\circ} \mathrm{C}$.

\section{Results and Discussion}

\section{Initiation of Culture}

Due to the considerable variations in the environmental conditions during different periods of the year, maturity status of the explant varied with season, hence response of explant to culture initiation also varied.

The best period for raising aseptic cultures was spring (February and March) when 93\% bud break was observed. Rainy season had almost an equal frequency of bud break but the rate of contamination was very high. Summers and winters were the least preferred seasons for the initiation of cultures as percentage of bud break was very low being 37 and 50\% respectively.

The dependence of bud break on external factors like the condition and the health of the mother plant. Size of explants also influenced the time taken for the bud break. Small sized explants $(5-7 \mathrm{~mm})$ did not respond well in the culture whereas explants of $25 \mathrm{~mm}$ took least number of days for initiation of sprouting probably due to greater concentration of endogenous hormones supporting bud break (fig-2).

\section{Shoot Multiplication}

For inducing sprouting, branch nodal explants were inoculated on MS medium with or without cytokinins. Nodal explants cultured on MS basal medium without any cytokinin took more time to sprout (30 days) whereas the nodal explants sprouted within 12 days of inoculation on MS medium supplemented cytokinin. The sprouted buds were excised from the nodal segment and transferred onto MS medium containing different concentrations and combinations of cytokinins like BAP $1.0,1.5 \& 2.0 \mathrm{mg} / \mathrm{l}$ and $\mathrm{Kn} 1.5 \& 2.0 \mathrm{mg} / \mathrm{l}$ (Table-1). Axillary shoot proliferation occurred on MS medium supplemented with different concentrations of BAP but $1.5 \mathrm{mg} / \mathrm{l}$ of BAP gave maximum multiplication rate. Earlier investigator Das and Pal., 2005 reported in vitro regeneration in B. balcooa via node segments in MS with BAP and Kn successfully. A significant increase in the 
shoot number was observed when BAP $(1.5 \mathrm{mg} / \mathrm{l})$ was used in combination with $\mathrm{Kn}(2.0 \mathrm{mg} / \mathrm{l})$ forming 3-4 shoots after 2 weeks (Fig. 3). The shoots multiplied further forming 5.6 \pm 0.547 shoots after 4 weeks (Fig. 4).

Table.1 Morphogenic response of branch nodal explants of Bambusa vulgaris at different concentration of cytokinins supplemented to MS medium

\begin{tabular}{|l|l|l|l|l|}
\hline BAP $(\mathrm{mg} / \mathrm{l})$ & Kn $(\mathrm{mg} / \mathrm{l})$ & Sprouting $(\%)$ & Shoot multiplication (per node) & Shoot length $(\mathrm{cm})$ \\
\hline 0.0 & 0.0 & 0.0 & 0.0 & 0.0 \\
\hline 1.0 & 0.0 & 35 & $1.6 \pm 0.547$ & $2.44 \pm 0.288$ \\
\hline 1.5 & 0.0 & 44 & $1.4 \pm 0.547$ & $2.62 \pm 0.192$ \\
\hline 2.0 & 0.0 & 42 & $2.4 \pm 0.547$ & $2.58 \pm 0.148$ \\
\hline 0.0 & 1.0 & 30 & $1.4 \pm 0.547$ & $1.62 \pm 0.228$ \\
\hline 0.0 & 2.0 & 40 & $1.8 \pm 0.447$ & $2.28 \pm 0.216$ \\
\hline 1.0 & 1.0 & 60 & $1.2 \pm 0.447$ & $2.78 \pm 0.130$ \\
\hline 1.5 & 1.0 & 75 & $2.4 \pm 0.547$ & $2.44 \pm 0.151$ \\
\hline 2.0 & 1.0 & 89 & $2.8 \pm 0.447$ & $2.56 \pm 0.114$ \\
\hline 1.0 & 2.0 & 88 & $2.6 \pm 0.547$ & $2.68 \pm 0.148$ \\
\hline 1.5 & 2.0 & 90 & $5.6 \pm 0.547$ & $5.86 \pm 0.230$ \\
\hline 2.0 & 2.0 & 80 & $1.6 \pm 0.547$ & $2.88 \pm 0.238$ \\
\hline
\end{tabular}

Table.2 Effect of IBA in rooting

\begin{tabular}{|l|l|l|l|}
\hline MS media & Rooting $(\%)$ & Rooting length $(\mathrm{cm})$ & Root Growth \\
\hline $1 / 2$ MS medium $+1 \mathrm{mg} /$ lit IBA & 34 & $4.84 \pm 0.230$ & ++ \\
\hline $1 / 2$ MS medium + $2 \mathrm{mg} /$ /it IBA & 60 & $8.78 \pm 0.192$ & ++++ \\
\hline $1 / 2$ MS medium $+3 \mathrm{mg} /$ lit IBA & 25 & $5.88 \pm 0.192$ & +++ \\
\hline
\end{tabular}

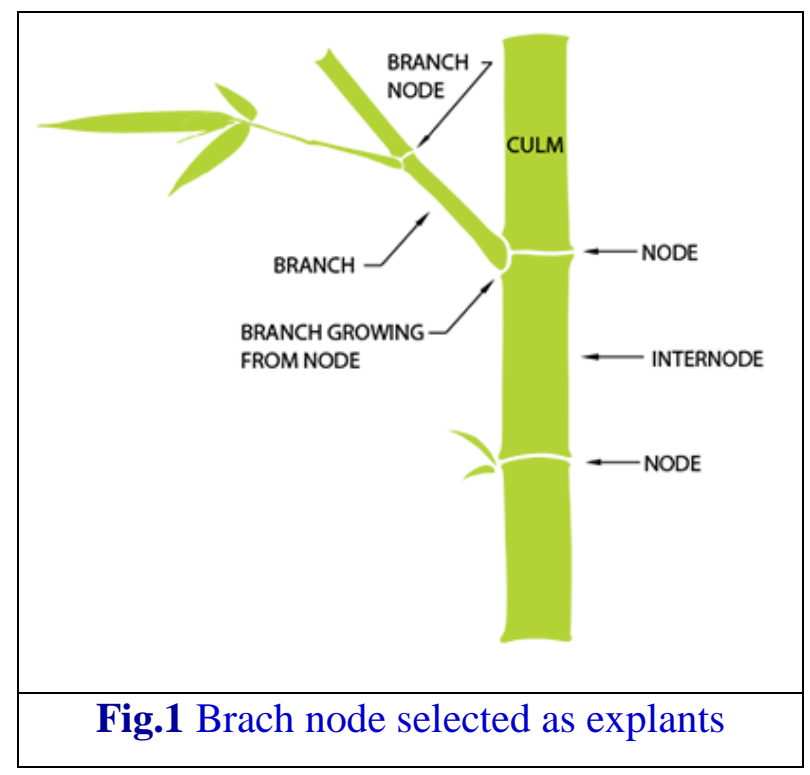




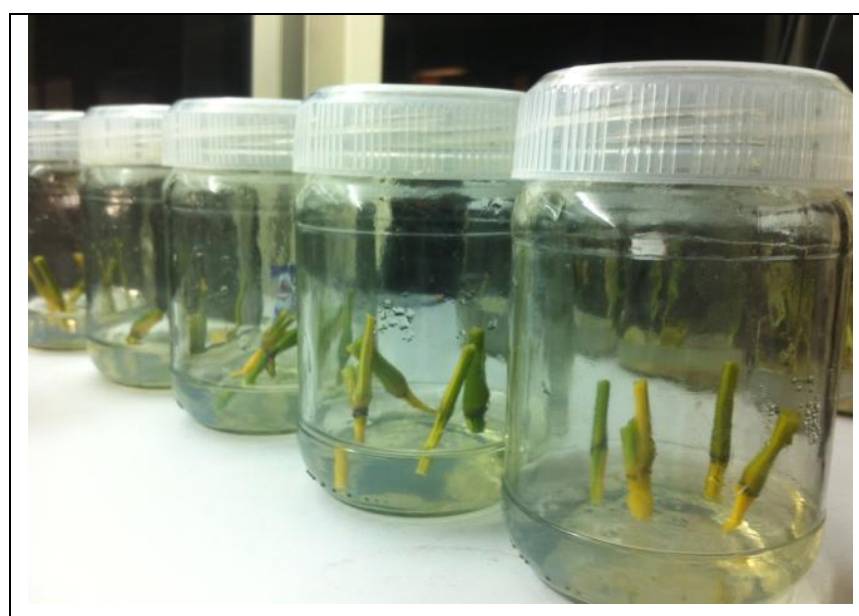

Fig.2 Explants were inoculated on MS medium

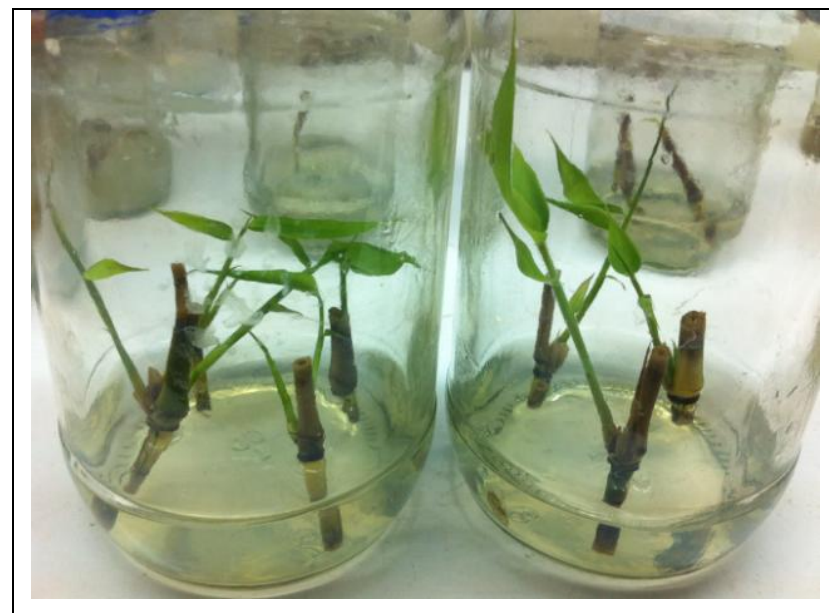

Fig.3 Shoot multiplication MS with BAP $(1.5 \mathrm{mg} / \mathrm{l})$ and $\mathrm{Kn}(2.0 \mathrm{mg} / \mathrm{l})$ after 2 weeks

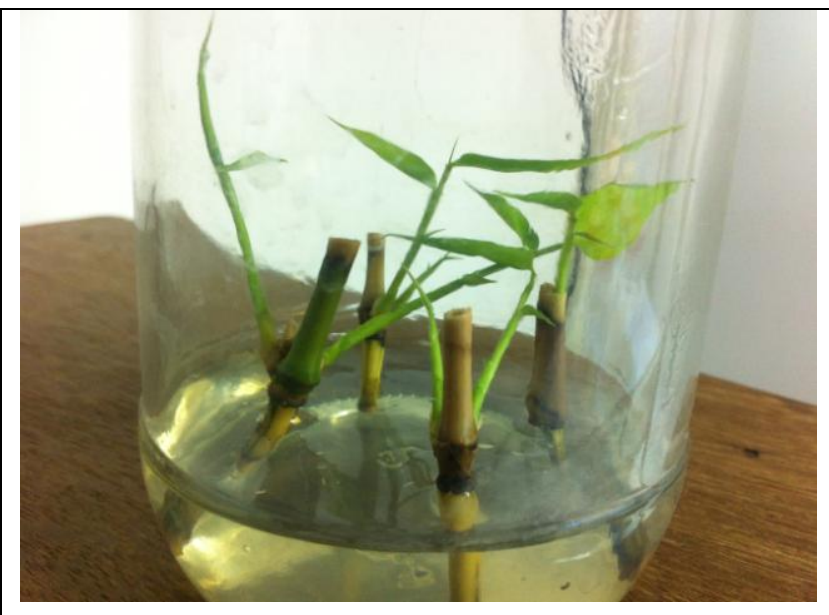

Fig.4 Shoot multiplication MS with BAP $(1.5 \mathrm{mg} / \mathrm{l})$ and $\mathrm{Kn}(2.0 \mathrm{mg} / \mathrm{l})$ after 4 weeks

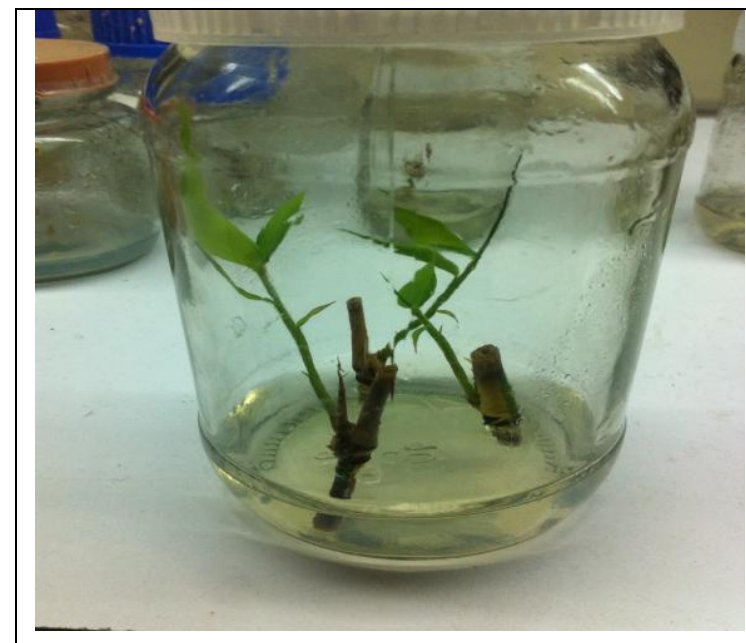

Fig.5 Effect of IBA $(2.0 \mathrm{mg} / \mathrm{l})$ in rooting

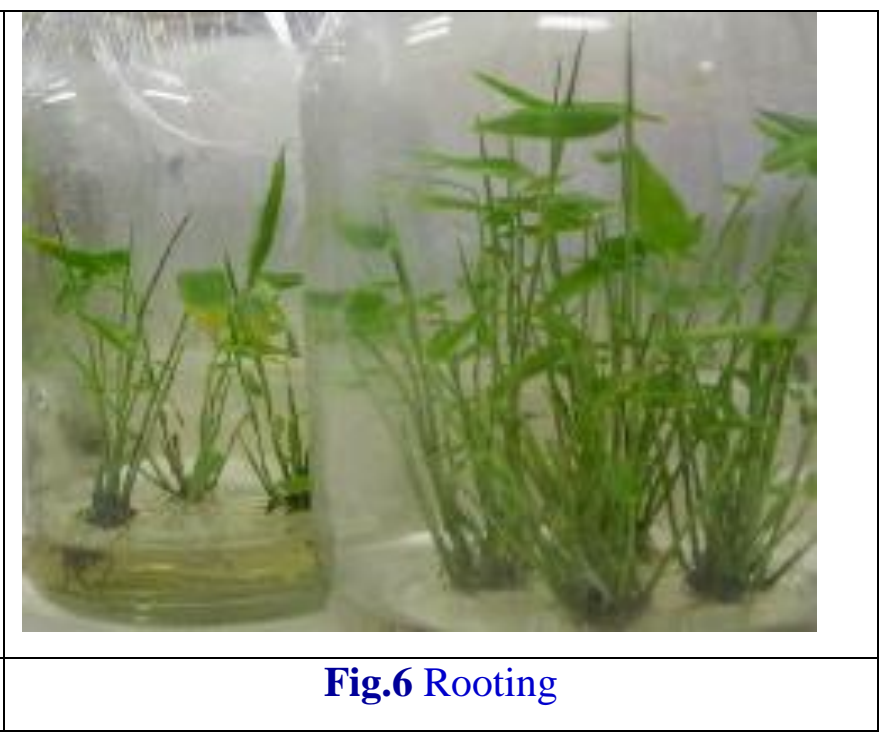




\section{Rooting and Acclimatization}

In general, rooting is a main bottleneck while carrying out in vitro multiplication of bamboos and has been a major problem to be worked out in this particular species. It was observed that rooting was more effectively induced when clusters of shoots rather than individual shoot were used.

The clumps of 3 to 4 shoots were inoculated on MS medium supplemented with different concentrations and combinations of auxins. In this studies different concentrations of IBA were used (Table-2). Out of all the auxins tried, initiation and growth of roots was observed on IBA $(2 \mathrm{mg} / \mathrm{l})$ supplemented medium where rooting occurred in $60 \%$ of cultures (Fig.5).

IBA treatments were used for promoting rooting on shoots of mature tissue derived bamboos viz. B. balcooa (Das and Pal, 2005; Islam and Rahman, 2005). Complete plantlets were hardened on soil: vermicompost (2:1) by gradually lowering the relative humidity and were successfully transferred from in vitro to natural environmental conditions with $80 \%$ survival rate (Patel $\&$ Suthar, 2014).

The plants showed well developed root and shoot systems and all the plants are thriving very well in field.

For in vitro propagation of bamboo, micropropagation is the only technique. According to Gielis and Oprins (2002), micropropagation is the best available technique and will become the standard for mass scale propagation, clone and resistance of bamboo.

It is now possible to micropropagate almost any selected bamboo at mass scale in a short time frame.

In order to develop appropriate micropropagation systems, further research is clearly required on propagation techniques to increase the multiplication rates of bamboo. In this studies branch node were good explants as mass scle production in short time with lost cost. BAP and Kn effects on break bud dormancy as well as shoot proliferation.

\section{Acknowledgments}

Authors are thankful to Dr. A.S. Gor, Principal, PSSHDA, Kadi for support and permission to work in Plant tissue culture lab. We are also thanks to Dr. K.R. Shah, Head of department for possible supports.

\section{Abbreviations}

MS media: Murashige and Skoog (1962) media BAP: 6-Benzylaminopurine

Kn: Kinetin

IBA: Indole- 3 Butyric acid

\section{References}

Brar, J., Anand, M., Sood, A., 2013. "In vitro seed germination of economically important edible bamboo dendrocalamus membra-naceus Munro," Indian Journal of Experimental Biology, 51 (1):8896.

Bystriakova, N., Kapos, V., Stapleton. C., Lysenko. V., 2003. "Bamboo Biodiversity," UNEPWCMC/INBAR, 6:1-18.

Christanty, L., Mailly, D., Kimmins, J. P. 1996. "Without bamboo, the land dies": Biomass, litterfall, and soil organic matter dynamics of a Javanese bamboo talunkebun system. Forest Ecology and Management, 87: 75-88.

Das, M., Pal, A. 2005. In vitro regeneration of Bambusa balcooa Roxb: factors affecting changes of morphogenetic competence in the axillary buds. Plant Cell Tiss. Organ Cult. 81:109-112.

Franklin, D. C., 2006. Wild bamboo stands fail to compensate for a heavy 1-year harvest of culm shoots. Forest Ecology and Management, 237:115118.

Gielis, J., Oprins, J. 2002. Micropropagation of temperate and tropical woody bamboos-from biotechnological dream to commercial reality. In: Bamboo for sustainable development. Proceedings of the Vth International Bamboo Congress and the VIth International Bamboo Workshop, San Jose, Costa Rica. 333-344

Islam, S.A.M.N., Rahman, M.M. 2005. Micro-cloning in commercially important six bamboo species for mass propagation and at a large scale. Plant Tiss. Cult. Biotech. 15:103-111.

Kassahun, E., 2000. The indigenous bamboo forests of Ethiopia: an overview. Ambio, 29: 518-521.

Kassahun, E., 2003. Ecological aspects and resource management of bamboo forests in Ethiopia. $\mathrm{PhD}$ Dissertation. Swedish University of Agricultural Sciences, Uppsala, St. Louis: MBG Press, 22.

Kleinhenz, V., Midmore, D. J. 2001. Aspects of bamboo agronomy. Advances in Agronomy, 74: 99-145.

Mailly, D., Christanty, L., Kimmins, J. P. 1997. "Without bamboo, the land dies": nutrient cycling and biogeochemistry of a Javanese bamboo talun- 
kebun system. Forest Ecology and Management, 91: 155-173.

Patel, M., Suthar, R. S. 2014. Micropropagation of garden rose (Rosa indicas L.) through different size of node explants Journal of life science research 1 (4): 107-111.

Wu, Z. Y., Raven, P. H., 2006. Flora of China: Poaceae. Beijing: Science Press

\section{How to cite this article:}

Hardik Gajjar, Akhil Raval, Hemangini Raval, Harikrushna Patel and Suthar Ramchandra. 2017. In Vitro Propagation of Bambusa vulgaris Through Branch Node. Int.J.Curr.Res.Aca.Rev. 5(8), 12-17.

doi: https://doi.org/10.20546/ijcrar.2017.508.002 